Revised : June, 26, 2021

Available online : June, 28, 2021

\title{
PENGARUH KERAGAMAN PRODUK DAN STORE ATMOSPHERE TERHADAP KEPUASAN KONSUMEN PADA KALIBATA COFFEE KALIANDA
}

\author{
Tamam $^{1}$, Selviana Hidayat ${ }^{2}$, Linda Safitri Hidayat ${ }^{3}$ \\ Sekolah Tinggi Ilmu Ekonomi Muhammadiyah Kalianda \\ Email : tamamdjamil@gmail.com
}

\begin{abstract}
Marketing is one of the main activities that need to be done by goods or servicescompanies, it is because marketing is a process of planning, determining prices, promoting and distributing in providing satisfaction to consumers.

This study aims to find out the influenceof $k$ eragaman products and store atmosphere (store atmosphere) on customer satisfaction in Kalibata Coffe Kalianda, both partially and simultaneously.

The research method used is a survey method with data collection techniques through interviews and questionnaires to 97 respondents by accidental sampling.

The results of this study showed that: (1) Product diversity positively influenced consumer satisfaction as evidenced by the calculated $t$ value of 4,116>ttable of 1,665 with a significance rate of $\mathbf{0 . 0 0 0}<\mathbf{0 . 0 5}$; (2) store atmosphere positively affects consumer satisfaction as evidenced by $t$ count of 7,558 > t table of 1,665 with a significance rate of

$0.000<0.05$; (3) The diversity of products and store atmosphere simultaneously positively affects consumer satisfaction, as evidenced by the value of $F$ count of 74,495 > the value of $f_{\text {table }} 3.09$ with a significant of $0.000<0.05$.

The conclusion of the study is that keragaman products and store atmosphere (store atmosphere) both partially and simultaneously affect the satisfaction of consumers in Kalibata Coffe Kalianda.
\end{abstract}

Keywords : Product Diversity, Store Atmosphere, and Customer Satisfaction

ABSTRAK : Pemasaran merupakan salah satu kegiatan pokok yang perlu dilakukan perusahaan barang atau jasa, hal disebabkan karena pemasaran merupakan suatu proses merencanakan, menentukan harga, mempromosikan dan mendistribusikan dalam memberikan kepuasan kepada konsumen.

Penelitian ini bertujuan untuk mengetahui pengaruh keragaman produk dan store atmosphere (suasana toko) terhadap kepuasan konsumen di Kalibata Coffe Kalianda, baik secara parsial dan simultan.

Metode penelitian yang digunakan adalah Metode survei dengan teknik pengumpulan data melalui wawancara dan kuisioner kepada 97 responden secara accidental sampling.

Hasil penelitian ini menunjukkan bahwa: (1) Keragaman produk berpengaruh positif terhadap kepuasan konsumen dibuktikan dari nilai t hitung sebesar 4,116 $>t_{\text {tabel }}$ sebesar 1,665 dengan tingkat signifikansi $\mathbf{0 , 0 0 0}<\mathbf{0 , 0 5}$; (2) store atmosphere berpengaruh positif terhadap kepuasan konsumen dibuktikan dengan $t$ hitung sebesar 7,558 $>t_{\text {tabel }}$ sebesar 1,665 dengan tingkat signifikansi $\mathbf{0 , 0 0 0}<\mathbf{0 , 0 5}$; (3) Keragaman produk dan store atmosphere secara simultan berpengaruh positif terhadap kepuasan konsumen, dibuktikan dengan nilai $\mathrm{F}$ hitung $\mathbf{7 4 , 4 9 5}>$ nilai $\mathrm{f}_{\text {tabel }} \mathbf{3 , 0 9}$ dengan signifikan sebesar $0,000<\mathbf{0 , 0 5}$.

Kesimpulan dari penelitian adalah bahwa keragaman produk dan store atmosphere (suasana toko) baik secara parsial dan simultan berpengaruh pasitif terhadap kepuasan konsumen di Kalibata Coffe Kalianda. 


\section{PENDAHULUAN}

Kondisi persaingan dunia saat ini menuntut pelaku bisnis atau pengusaha untuk mampu menyesuaikan diri dengan keadaan global. Untuk itu, pengusaha harus pandai melihat peluang serta menentukan strategi yang tepat untuk memenangkan persaingan tersebut. Salah satu tujuan mendirikan usaha adalah mendapatkan kepercayaan konsumen serta memperoleh keuntungan yang sebesarbesarnya.

Kegiatan menganalisis, merencanakan, menerapkan dan mengendalikan terhadap program yang dirancang untuk menciptakan dan membangun hubungan yang saling menguntungkan dengan pasar sasaran dengan maksud untuk mencapai tujuan suatu organisasi merupakan bagian dari manajemen pemasaran (Kotler, 2002)

Menurut Kotler dan Keller (2016) mengungkapkan bahwa bauran pemasaran tidak hanya mencakup $4 \mathrm{p}$ (product), harga (price), tempat (place), dan promosi (promotion), terdapat $4 \mathrm{p}$ lain dalam modern marketing mix terdiri dari people (orang) ,process (proses), programs (program) dan perormance (kinerja).

\section{Pengertian Produk}

Menurut Kotlerdalam buku H.Abdul Manaf (2016:255):
Produk adalah segala sesuatu yang dapat ditawarkan di pasar, untuk memuaskan kebutuhan dan keinginan konsumen. Produk terdiri atas barang, jasa, pengalaman, events, orang, tempat, kepemilikan, organisasi, informasi dan ide. lainnya.

Menurut Stanton yang dikutip oleh Buchari Alma (2014:139), mendefinisikan produk sebagai seperangkat atribut baik terwujud maupun tidak terwujud, termasuk didalmmya masalah warna, harga, nama baik pabrik, nama baik cafe yang menjual (pengecer), dan pelayanan pabrik serta pengecer, yang diterima oleh pembeli guna memuaskan keinginannya.

Menurut (Hakim \& Suhendi, 2012),seragaman produk adalah kelengkapan produk yang menyangkut kedalaman, luas, dan kualitas produk yang ditawarkan,

Setiap konsumen memiliki selera makan yang tidak selalu sama,

Untuk itu cafe menyediakan menu yang beranekaragam, akan lebih memudahkan cafe untuk menarik konsumen agar bersantap di tempatnya. Karena, semakin banyak pilihan yang disediakan oleh sebuah cafe, maka akan semakin memudahkan konsumen untuk memilih menu atau produk sesuai keinginannya. Hal ini tentu menjadi kepuasan tersendiri 
Revised : June, 26, 2021

Available online : June, 28, 2021

bagi konsumen dalam menentukan pilihan menu atau produk yang akan dia konsumsi.

\section{Indikator keragaman produk}

Indikator keragaman produk dalam penelitian ini adalah :

a. Jenis produk

b. Kualitas,

c. Kelengkapan,

d. Ketersediaan produk.

Menurut Benson (2007:136)

\section{Pengertian Store Atmosphere / Suasana}

Toko

Atmosphere atau suasana merupakan fasilitas dalam sebuah ruangan yang diberikan pada cafe atau department store kepada konsumennya. Suasana cafe memiliki peran penting dalam menciptakan ketertarikan minat konsumen dalam berkunjung dengan memfasilitasi dan memberikan tampilan yang unik seingga konsumen merasa nyaman.

Menurut Levy dan Weitz (2001:576) store atmosphere adalah mendesain suatu lingkungan melalui pencahayaan, desain dan warna, musik, dan penciuman/aroma untuk merangsang persepsi dan emosi dari konsumen dan pada akhirnya untuk mempengaruhi kepuasan belanja mereka. Menurut Sutisna (2001:164) store atmosphere adalah penataan ruang dalam dan ruang luar yang dapat menciptakan kenyamanan bagi konsumen.

Dari pengertian diatas dapat disimpulkan bahwa store atmosphere adalah mendesain suatu lingkungan melalui pencahayaan, desain dan warna, musik, dan penciuman/aroma untuk merangsang persepsi dan emosi dari konsumen dan pada akhirnya untuk mempengaruhi kepuasan belanja mereka

\section{Indikator Store Atmosphere}

Indikator Store Atmosphere dalam penelitian inim mengacu pada Levy dan Weitz (dalam Wibowo.2012;37)

1. Pencahayaan

2. Desain dan Warna

3. Aroma

4. Musik

\section{Pengetian Kepuasan Konsumen}

Menurut Zeithaml dan Bitner (2000:75) Kepuasan Konsumen adalah suatu respon atau tanggapan konsumen mengenai kebutuhan, kepuasan merupakan penilaian mengenai ciri atau keistimewaan produk atau jada yang menyediakan tingkat kesenangan konsumen berkaitan dengan pemenuhan konsumsi konsumen.

Kalibata Coffe menyediakan menu yang beranekaragam, akan lebih memudahkan 
Revised : June, 26, 2021

Available online : June, 28, 2021

cafe untuk menarik konsumen agar

konsumen (Hakim, 2021).

bersantap di tempatnya. Karena, semakin banyak pilihan yang disediakan oleh sebuah cafe, maka akan semakin memudahkan konsumen untuk memilih menu atau produk sesuai keinginannya. Hal ini tentu menjadi kepuasan tersendiri bagi konsumen dalam menentukan pilihan menu atau produk yang akan dia konsumsi.

Fasilitas dalam sebuah ruangan yang diberikan pada cafe atau department store kepada konsumennya. Suasana cafe memiliki peran penting dalam menciptakan ketertarikan minat konsumen dalam berkunjung dengan memfasilitasi dan memberikan tampilan yang unik seingga konsumen merasa nyaman. Mendesain atmosphere pada suatu lingkungan melalui pencahayaan, desain dan warna, musik, dan penciuman/aroma untuk merangsang persepsi dan emosi dari konsumen dan pada akhirnya untuk mempengaruhi kepuasan belanja mereka (Levy \& Weitz, 2001).

Respon atau tanggapan konsumen mengenai kebutuhan, kepuasan merupakan penilaian mengenai ciri atau keistimewaan produk atau jada yang menyediakan tingkat kesenangan konsumen berkaitan dengan pemenuhan konsumsi konsumen merupakan bagian dari suatu kepuasan

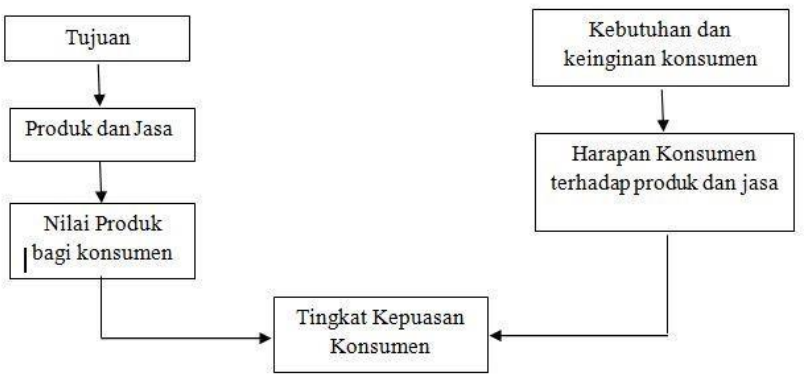

Gambar 1. Model Kepuasan Konsumen

\section{Indikator Kepuasan Pelanggan}

Perusahaan harus memiliki kemampuan penyediaan pelayanan yang baik dalam memenuhi harapan konsumennya secara konsisten.. (Hawkins dan Lonney (dikutip Tjiptono 2004;101)). Oleh karena itu terdapat 3 indikator untuk mengukur kepuasan konsumen yaitu :

1. Kesesuaian Harapan

2. Minat berkunjung kembali

3. Kesediaan merekomendas

\section{Kerangka Hipotesis}

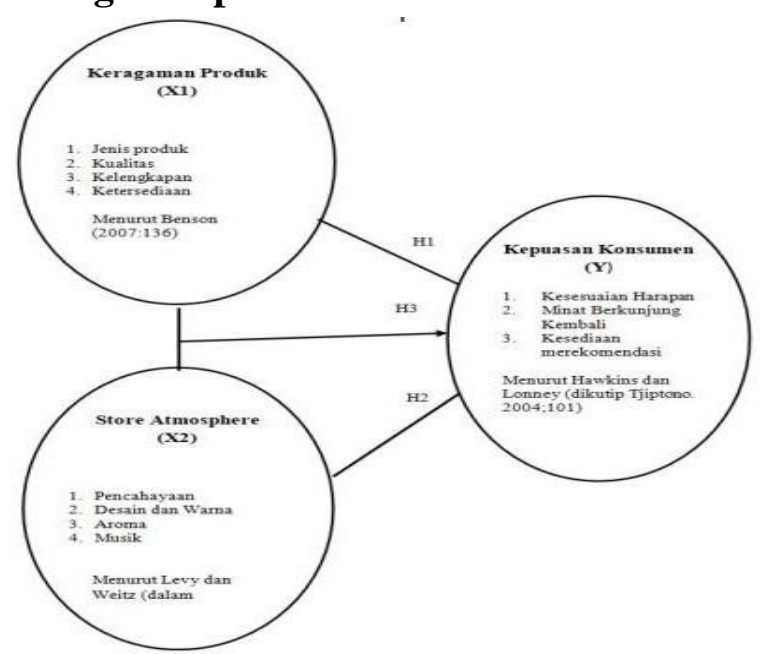

Gambar 2. Kerangka Hipotesis 
Revised : June, 26, 2021

Available online : June, 28, 2021

\section{Hipotesis}

Hipotesis dalam penelitian ini adalah sebagai berikut ;

H1 : Keragaman Produk berpengaruh positif terhadap kepuasan konsumen pada Kalibata Coffe Kalianda.

H2 : Store Atmosphere berpengaruh positif terhadap kepuasan konsumen pada Kalibata Coffe Kalianda.

H3 : Keragaman Produk dan Store Atmosphere secara simultan berpengaruh positif terhadap kepuasan konsumen pada Kalibata Coffe Kalianda

\section{METODE PENELITIAN}

Jenis penelitian yang digunakan adalah Metode survei dengan teknik pengumpulan data melalui wawancara dan kuisioner kepada 97 responden/konsumen secara accidental sampling.

\section{Populasi dan sampel}

Populasi pada Kalibata Coffe Kalianda Lampung Selatan sebagaimana tabel dibawah :

Tabel 1 : Jumlah Konsumen Kalibata Coffe Kalianda pada tahun 2020

\begin{tabular}{|c|c|}
\hline Bulan & Tahun 2020 \\
\hline Januari & 3.074 \\
\hline Februari & 2.782 \\
\hline Maret & 2.009 \\
\hline April & 2.986 \\
\hline Mei & 3.102 \\
\hline Juni & 3.116 \\
\hline Juli & 3.980 \\
\hline Agustus & 3.124 \\
\hline September & 3.145 \\
\hline Oktober & 3.213 \\
\hline Nopember & 3.200 \\
\hline Jumlah & $\mathbf{3 3 . 7 3 1}$ \\
\hline Rata-Rata & $\mathbf{3 . 0 6 6}$ \\
\hline
\end{tabular}

Sumber: Kalibata Coffe

bagian dari jumlah dan karakteristik yang di miliki oleh populasi tersebut, Sugiono (2008:116). Metode pengambilan sampelnya menggunakan metode Slovin dalam (bungin.2008:105) yaitu :

$$
n=\frac{\mathrm{N}}{N(d)^{2}+1}
$$

Keterangan:

$\mathrm{n} \quad=$ Jumlah sampel yang dicari

$\mathrm{N}=$ Jumlah populasi

$\mathrm{D}=$ Nilai presesi yang di gunakan yaitu $10 \%$

$$
\begin{aligned}
& n=\frac{3.066}{3.066(0,1)^{2}+1} \\
& n=\frac{3.066}{3.066(0,01)+1}=96,8 \\
& =97 \text { responden }
\end{aligned}
$$


Revised : June, 26, 2021

Available online : June, 28, 2021

\section{Teknik Pengumpulan Instrumen}

Instrumen pengukuran yang digunakan pada penelitian ini adalah menggunakan skala likert sebagai berikut :
A. Sangat Setuju (SS)
: skor 5
B. Setuju (S)
: skor 4
C. Netral $(\mathrm{N})$
: skor 3
D. Tidak setuju (TS)
: skor 2
E. Sangat ridak setuju (STS) : skor 1

\section{Metode Analisis}

Metode analisis data dan pembahasan yang digunakan dalam penelitian ini baik Analisis Deskriptif (Kualitatif) dan Analisis Kuantitatif dengan menggunakan Statistical Package for Social Sciens 24 (SPSS 24).

\section{HASIL DAN PEMBAHASAN}

a. Hasil Uji Validitas Instrumen Kuesioner sebagaimana tebel berikut :

Tabel 2 : Hasil Uji Validitas

\begin{tabular}{|c|c|c|c|c|}
\hline NO & $\begin{array}{c}\text { Variabel Dan } \\
\text { Indikatornya }\end{array}$ & $\begin{array}{c}\mathrm{r}_{\text {hitun }} \\
\mathrm{g}\end{array}$ & $\begin{array}{c}\mathrm{r}_{\text {tabel }} \\
(0,05) \\
97\end{array}$ & $\begin{array}{c}\text { Ketera } \\
\text { ngan }\end{array}$ \\
\hline $\mathbf{1}$ & $\begin{array}{c}\text { Keragaman } \\
\text { Produk (X1) }\end{array}$ & & & \\
\hline \multirow{4}{*}{} & Jenis Produk & 0,55 & 0,19 & Valid \\
& & 7 & 8 & \\
\cline { 2 - 5 } & Kualitas & 0,54 & 0, & Valid \\
& & 5 & 198 & \\
\cline { 2 - 5 } & Kelengkapan & 0,64 & 0, & Valid \\
& & 7 & 198 & \\
\cline { 2 - 5 } & Ketersedaiaan & 0,37 & 0, & Valid \\
& & 8 & 198 & \\
\hline 2 & Store & & & \\
& Atmospere & & & \\
\hline
\end{tabular}

\begin{tabular}{|c|c|c|c|c|}
\hline \multicolumn{5}{|c|}{$\overline{(\bar{X} 2)}$} \\
\hline & Pencahayaan & $\begin{array}{c}0,45 \\
8\end{array}$ & $\begin{array}{c}0 \\
198\end{array}$ & Valid \\
\hline & $\begin{array}{c}\text { Desain Dan } \\
\text { Warna }\end{array}$ & $\begin{array}{c}0,44 \\
7\end{array}$ & $\begin{array}{c}0, \\
198\end{array}$ & Valid \\
\hline & Aroma & $\begin{array}{c}0,48 \\
3\end{array}$ & $\begin{array}{c}0 \\
198\end{array}$ & Valid \\
\hline & Musik & $\begin{array}{c}0,42 \\
6\end{array}$ & $\begin{array}{c}0, \\
198\end{array}$ & Valid \\
\hline 3 & $\begin{array}{c}\text { Kepuasan } \\
\text { Konsumen } \\
(\mathbf{Y})\end{array}$ & & & \\
\hline & $\begin{array}{c}\text { Kesesuaian } \\
\text { Harapan }\end{array}$ & $\begin{array}{c}0,61 \\
9\end{array}$ & $\begin{array}{c}0, \\
198\end{array}$ & Valid \\
\hline & $\begin{array}{c}\text { Minat } \\
\text { Berkunjung } \\
\text { Kembali }\end{array}$ & $\begin{array}{c}0,59 \\
1\end{array}$ & $\begin{array}{c}0, \\
198\end{array}$ & Valid \\
\hline & $\begin{array}{c}\text { Kesediaan } \\
\text { Merekomenda } \\
\text { si }\end{array}$ & $\begin{array}{c}0,67 \\
3\end{array}$ & $\begin{array}{c}0, \\
198\end{array}$ & Valid \\
\hline
\end{tabular}

Sumber data: Data Primer Yang Diolah 2020

Dari Hasil uji validitas instrumen pada penelitian ini menunjukkan bahwa semua instrumen kuesioner valid (kuat) dan dapat digunakan.

b. Hasil Uji Reliabilitas Instrumen Kuesioner sebagaimana tabel berikut :

Tabel 3 : Hasil Uji Reliabilitas

\begin{tabular}{|c|c|c|c|}
\hline Variabel & Alpha & $\begin{array}{c}\text { Kriteria } \\
\text { Croanboach } \\
\text { Alpha }\end{array}$ & Keterangan \\
\hline $\begin{array}{c}\text { Keragaman } \\
\text { produk }\end{array}$ & $\mathbf{0 , 6 6 4}$ & $\mathbf{0 , 6 0 0}$ & Reliabel \\
\hline $\begin{array}{c}\text { Store } \\
\text { atmosphere }\end{array}$ & $\mathbf{0 , 6 9 1}$ & $\mathbf{0 , 6 0 0}$ & Reliabel \\
\hline $\begin{array}{c}\text { Kepuasan } \\
\text { konsumen }\end{array}$ & $\mathbf{0 , 7 1 8}$ & $\mathbf{0 , 6 0 0}$ & Reliabel \\
\hline
\end{tabular}

Sumber data: Data Primer Yang Diolah 2020 


\section{Tabel 5 : Hasil Analisis Korelasi Berganda}

\begin{tabular}{|c|c|c|c|c|}
\hline \multicolumn{5}{|c|}{ Correlations } \\
\hline & & $\begin{array}{c}\text { keraga } \\
\text { man } \\
\text { produk }\end{array}$ & $\begin{array}{c}\text { store } \\
\text { atmospere }\end{array}$ & $\begin{array}{c}\text { kepuas } \\
\text { an } \\
\text { konsum } \\
\text { en }\end{array}$ \\
\hline \multirow{3}{*}{$\begin{array}{l}\text { Keragaman } \\
\text { Produk }\end{array}$} & \multirow{3}{*}{$\begin{array}{l}\text { Pearson } \\
\text { Correlation } \\
\text { Sig. (2- } \\
\text { tailed) } \\
\mathrm{N}\end{array}$} & 1 & $.530^{* *}$ & $.615^{*}$ \\
\hline & & & .000 & .000 \\
\hline & & 97 & 97 & 97 \\
\hline \multirow{3}{*}{$\begin{array}{l}\text { Store } \\
\text { Atmospere }\end{array}$} & \multirow{3}{*}{$\begin{array}{l}\text { Pearson } \\
\text { Correlation } \\
\text { Sig. (2- } \\
\text { tailed) } \\
\mathrm{N}\end{array}$} & $.530^{* *}$ & 1 & $.737^{* *}$ \\
\hline & & .000 & & .000 \\
\hline & & 97 & 97 & 97 \\
\hline \multirow{3}{*}{$\begin{array}{l}\text { Kepuasan } \\
\text { Konsumen }\end{array}$} & \multirow{3}{*}{$\begin{array}{l}\text { Pearson } \\
\text { Correlation } \\
\text { Sig. (2- } \\
\text { tailed) } \\
\mathrm{N}\end{array}$} & $.615^{\star *}$ & $.737^{* *}$ & 1 \\
\hline & & .000 & .000 & \\
\hline & & 97 & 97 & 97 \\
\hline
\end{tabular}

Dari tabel 5 diatas analisis korelasi diatas, hubungan, kuat dan lemahnya antara variabel bebas terhadap variabel terikat adalah sebagai berikut:

1. Koefisien korelasi (r) antara keragaman produk terhadap kepuasan konsumen = 0,615, memiliki hubungan positif (+), Setelah dikonsultasikan dengan interprestasi nilai $\mathrm{r}$ dengan tingkat interval 0,60 - 0,799 dengan tingkat pengaruh,

Kuat.

2. Koefisien korelasi (r) antara store atmosphere terhadap kepuasan konsumen $=\mathbf{0 , 7 3 7}$ memiliki hubungan positif $(+)$, Setelah dikonsultasikan dengan interprestasi nilai $r$ dengan tingkat interval 0,60 - 0,799 dengan tingkat pengaruh,

Kuat.

\section{Koefesien Determinasi $\left(\mathbf{R}^{\mathbf{2}}\right)$}

Koefisien determinasi $\left(\mathrm{R}^{2}\right)$ pada intinya mengukur seberapa besar persepsi konsumen terhadap model variabel bebas terhadap variabel terikat. Hasil koefisien determinasi dalam penelitian ini sebagaimana tabel berikut :

\section{Tabel 6 : Koefesien Determinasi}

\begin{tabular}{|c|c|c|c|c|}
\hline \multicolumn{5}{|c|}{ Model Summary } \\
\hline Model & $\mathrm{R}$ & R Square & $\begin{array}{c}\text { Adjusted R } \\
\text { Square } \\
\end{array}$ & $\begin{array}{c}\text { Std. Error of the } \\
\text { Estimate }\end{array}$ \\
\hline 1 & $.783^{\mathrm{a}}$ & 613 & .605 & .82144 \\
\hline
\end{tabular}

Dari hasil perhitungan dengan menggunakan program SPSS Versi 24, dapat diketahui bahwa koefesien determinasi ( $R^{2}$ ) yang diperoleh sebesar 0,613 hal ini berarti 61,3\%. Dengan demikian dapat dikatakan bahwa kontribusi Keragaman Produk (X1) dan Store Atmosphere (X2) terhadap Kepuasan $\begin{array}{llll}\text { Konsumen (Y). } & \text { sisanya } & \mathbf{3 8 , 7} & \%\end{array}$ dipengaruhi oleh variabel lainnya yang tidak diteliti dalam penelitian ini.

\section{Hasil Uji Hipotesis}

1. Uji Parsial

\section{Tabel 7 : Hasil Uji t Parsial}

\begin{tabular}{|c|c|c|c|c|c|c|}
\hline \multicolumn{7}{|c|}{ Coefficients $^{a}$} \\
\hline & & \multicolumn{2}{|c|}{$\begin{array}{l}\text { Unstandardized } \\
\text { Coefficients }\end{array}$} & \multirow{2}{*}{\begin{tabular}{|c|}
$\begin{array}{c}\text { Standardize } \\
d \\
\text { Coefficients }\end{array}$ \\
Beta \\
\end{tabular}} & \multirow[b]{2}{*}{$t$} & \multirow[b]{2}{*}{ Sig. } \\
\hline \multicolumn{2}{|c|}{ Model } & $B$ & Std. Error & & & \\
\hline \multirow[t]{3}{*}{1} & (Constant) & 2.886 & .962 & & 3.000 & .003 \\
\hline & Keragaman Produk & 271 & .066 & 311 & 4.116 & .000 \\
\hline & Store Atmosphere & 317 & .042 & .572 & 7.558 & .000 \\
\hline
\end{tabular}


Revised : June, 26, 2021

Available online : June, 28, 2021

\section{Variabel keragaman produk (X1)}

Hasil uji $t_{\text {tabel }}$ variabel $\mathrm{X}_{1}$ ( keragaman produk ) diperoleh nilai $t_{\text {hitung }}=\mathbf{4 , 1 1 6}$ tingkat signifikansi $\mathbf{0 , 0 0 0}$. Dengan menggunakan batas signifikansi $\mathbf{0 , 0 5}$ didapat $\mathrm{t}_{\text {tabel }}$ sebesar 1,665. Ini berarti $\mathrm{t}_{\text {hitung }}$ $>$ dari $t_{\text {tabel }}$ yang berarti hipotesis $1\left(\mathrm{H}_{1}\right)$ Diterima. Arah koefisien regresi positif yang signifikan berarti bahwa keragaman produk berpengaruh positif terhadap kepuasan konsumen. Dengan demikian hipotesis yang menyatakan keragaman produk dan store atmosphere berpengaruh positif terhadap kepuasan konsumen pada kalibata coffe kalianda terbukti kebenarannya.

\subsection{Variabel Store Atmospere (X2)}

Hasil uji $\mathrm{t}$ tabel variabel $\mathrm{X}_{2}$ (Store Atmosphere) diperoleh nilai $t_{\text {hitung }}=\mathbf{7 , 5 5 8}$ tingkat signifikansi $\mathbf{0 , 0 0 0}$. Dengan menggunakan batas signifikansi $\mathbf{0 , 0 5}$ didapat $t_{\text {tabel }}$ sebesar 1,665. Ini berarti $t_{\text {hitung }}$ $>$ dari $t_{\text {tabel }}$ yang berarti hipotesis $2\left(\mathrm{H}_{2}\right)$ Diterima. Arah koefisien regresi positif yang signifikan berarti store atmosphere berpengaruh positif pada kepuasan konsumen. Dengan demikian hipotesis yang menyatakan keragaman produk dan store atmosphere berpengaruh positif terhadap kepuasan konsumen pada kalibata coffe kalianda terbukti

kebenarannya.

2. Uji Simultan F

Tabel 8 : Hasil Uji F (simultan)

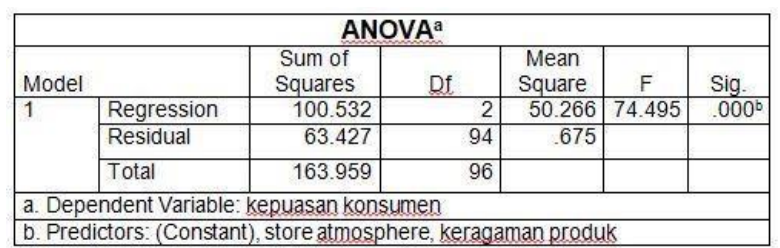

Berdasarkan tabel 8 diatas analisis varian (anova) ditampilkan uji $\mathrm{f}_{\text {hitung }}$ yang dapat dipergunakan untuk memprediksi Keragaman produk dan Store atmosphere terhadap Kepuasan Konsumen.

Dari perhitungan didapat $f_{\text {hitung }}$ sebesar 74,495 dengan tingkat signifikansi sebesar $0,05 \%$ dan $\mathrm{df}_{1}=2$ dan $\mathrm{df}_{2}=94$ didapat nilai $f_{\text {tabel }}$ 3,09 karena nila $f_{\text {hitung }}$ $\mathbf{7 4 , 4 9 5}>$ nilai $f_{\text {tabel }}$ 3,09. Dengan demikian hipotesis yang menyatakan keragaman produk dan store atmosphere secara bersama sama berpengaruh positif terhadap kepuasan konsumen pada kalibata coffe kalianda terbukti kebenarannya.

\section{Pembahasan}

Dari hasil tersebut selanjutnya diperoleh bahwa dari dua variabel independen yaitu keragaman produk dan store atmosphere memiliki pengaruh yang signifikan terhadap Kepuasan konsumen pada Kalibata Coffe Kalianda. Penjelasan 
Revised : June, 26, 2021

Available online : June, 28, 2021

dari masing-masing variabel dijelaskan

sangat baik. Dengan demikian pengujian sebagai berikut:

hipotesisi 3 diterima.

\section{Pengaruh Keragaman Produk}

\section{terhadap Kepuasan Konsumen}

Pengujian hipotesis 1 menunjukkan adanya pengaruh positif dan signifikan keragaman produk terhadap kepuasan konsumen Kalibata Coffe Kalianda hasil ini menunjukkan penilaian yang baik mengenai keragaman produk Dengan demikian pengujian hipotesisi 1 diterima

\section{Pengaruh Store Atmosphere terhadap Kepuasan Konsumen}

Store Atmosphere memiliki pengaruh yang positif dan signifikan terhadap kepuasan konsumen. Terbukti dengan pengujian hipotesisi 2, hal ini berarti bahwa responden akan menilai tentang Kepuasan Konsumen pada Kalibata Coffe Kalianda cukup baik. Dengan demikian pengujian hipotesisi 2 diterima.

\section{Pengaruh Keragaman Produk dan Store Atmosphere terhadap Kepuasan Konsumen}

Keragaman Produk dan Store Atmospere memiliki pengaruh yang positif dan signifikan terhadap Kepuasan Konsumen. Terbukti dengan pengujian hipotesisi 3, hal ini berarti bahwa responden akan menilai dan merasakan Keragaman Produk dan Store Atmospere terhadap Kepuasan Konsumen pada Kalibata Coffe Kalianda

\section{Kesimpulan}

Dari pembahasan yang telah diuraikan, maka dapat ditarik kesimpulan sebagai berikut :

Hasil penelitian ini menunjukkan bahwa:

1. Keragaman produk berpengaruh positif terhadap kepuasan konsumen dibuktikan dari nilai t hitung sebesar 4,116 > t tabel sebesar 1,665 dengan tingkat signifikansi $\mathbf{0 , 0 0 0}<\mathbf{0 , 0 5}$;

2. Store atmosphere berpengaruh positif terhadap kepuasan konsumen dibuktikan dengan $\mathrm{t}$ hitung sebesar $\mathbf{7 , 5 5 8}>t_{\text {tabel }}$ sebesar 1,665 dengan tingkat signifikansi $\mathbf{0 , 0 0 0}<\mathbf{0 , 0 5}$;

3. Keragaman produk dan store atmosphere secara simultan berpengaruh positif terhadap kepuasan konsumen, dibuktikan dengan nilai $\mathrm{F}$ hitung $\mathbf{7 4 , 4 9 5}>$ nilai $\mathrm{f}_{\text {tabel }}$ 3,09 dengan signifikan sebesar $0,000<0,05$.

\section{Saran}

Berdasarkan hasil penelitian yang telah dilakukan, dan mengacu pada hasil analisa secara kualitatif dari indikator masingmasing variabel, maka peneliti mengajukan saran, sebagai berikut : 
1. Sebaiknya pihak manajemen Kalibata Coffe Kalianda hendaknya lebih meningkatkan keragaman produk terutama pada ketersediaan produk secara lengkap, baik dalam makanan dan minuman agar dapat memenuhi kebutuhan dan keinginan konsumen.

2. Untuk pencahayaan di dalam maupun di luar ruangan cafe perlu di tingkatkan, selain itu kalibata coffe juga perlu dilengkapi dengan berbagai jenis lampu yg lebih terang guna menunjang kenyamanan konsumen saat berada.

3. Sebaiknya pihak manajemen Kalibata Coffe Kalianda lebih mengaplikasikan desain dan warna ruangan yg unik dan menarik agar terlihat indah dan tidak membosankan bagi konsumen.

4. Sebaiknya pihak manajemen Kalibata Coffe Kalianda lebih memperhatikan aroma ruangan yang menurut responden dalam penelitian ini kurang baik, seperti memberikan parfum ruangan yang mengeluarkan bau wangi-wangian setiap beberapa menit, atau aroma alami seperti bunga lavender, dll. hal ini berguna untuk meningkatkan kenyamanan konsumen saat berada.

5. Sebaiknya Kalibata Coffe Kalianda juga perlu memperhatikan elemen elemen penunjang lainnya, seperti menghibur konsumen berada dengan alunan musik yang menambah kepuasan dan kenyamanan konsumen, di tambah lagi memperkenankan konsumen untuk ikut bernyanyi.

6. Pihak manajemen kalibata coffe kalianda juga sebaiknya memperhatikan pelayanan karyawan terhadap konsumen dan segi produk yang disajikan agar tidak membosankan. pelayanan yang ramah dan tanggap sangat mempengaruhi kepuasan konsumen.

\section{DAFTAR PUSTAKA}

Ade Aminudin Charlis. 2013. Pengaruh Keanekaragaman Produk, Kualitas pelayanan, dan Kepercayaan Terhadap Kepuasan Konsumen Giant Supermarket Puri Anjasmoro Semarang. (Universitas Pandanaran, Jurnal Ekonomi dan Bisnis, Vol 2, Hal 2, Januari 2013).

Buchari Alma. 2014. Manajemen Pemasaran dan Pemasaran Jasa. Bandung: Penerbit Alfabeta.

David Harinto dan Dr Hartono Subagio SE., MM. Pengaruh Kualitas Layanan,Brand image, dan Store Atmosfer terhadap kepuasan konsumen Kedai Deja-Vu Surabaya. (Jurnal Manajemen pemasaran Vol 1, Hal 1, Maret 2013)

Daryanto. 2011. Manajemen Pemasaran Jilid kedua. Alih Bahasa : Andreas Winardi. Bandung: Alfabet 
Revised : June, 26, 2021

Available online : June, 28, 2021

Dewi, Rohma ningsih. 2016 Pengaruh

Suasana Toko, Kualitas Pelayanan

Dan Keragaman Produk Terhadap

Kepuasan Konsumen (Studi Pada

Granny's Nest Cafe And Resto Di

Bandar Lampung) Administrasi

Bisnis. Fakultas Ekonomi Dan

Bisnis. Universitas Lampung.

Lampung

Djaslim Saladin. 2012. Intisari Pemasaran dan Unsur-Unsur Pemasaran (Ringkasan Praktis Teori dan Tanya Jawab), Cetakan Keempat, Linda Karya, Bandung.

Engel, James, F, Roger D. Blackwell, dan Paul W. Miniard. 2013. Perilaku Konsumen. Edisi Keenam. Jilid 1. Penerbit Binarupa Aksara. Jakarta.

Fandy Tjiptono. 2013. Pemasaran Jasa, Bayumedia, Malang.

Hakim, L. N., \& Suhendi, A. (2012).

Analisis Location Quotion versus

Sumbangan Terhadap Pendapatan

Domestik Regional Bruto dalam

Penentuan Kawasan Ekonomi Basis

di Provinsi Lampung. GEMA : Jurnal

Gentiaras Manajemen Dan

Akuntansi, 13(2), 120-134.

https://doi.org/10.47768/gema.v13i2.

239

Husein Umar. 2011. Metode Penelitian untuk Skripsi dan Tesis Bisnis, Jakarta: Rajawali Pers.

Imam Ghozali. 2006. Aplikasi Analisis Multivariate Dengan Program SPSS, Semarang: Badan Penerbit Undip.

Kotler, Philip dan Keller, Kevin Land. 1990. Manajemen Pemasaran Jilid 1

Edisi Jakarta: PT Indeks

Kotler, Philip \& Keller, Kevin Lane. (2009). Manajemen Pemasaran Edisi 13. (Alih bahasa: Bob Sabran MM). Jakarta: Erlangga

Kotler, Philip dan Gery Amstrong. 2014. Principles of Marketing, Global Edition, 14 Edition, Pearson Education.
Mowen, Jhon C. dan Michael Minor. 2002. Perilaku Konsumen Jilid Pertama. Alih Bahasa: Dwi Kartini. Jakarta: Erlangga

Noor Alamsyah. 2013. Analisis Pengaruh Keragaman Produk, Harga dan Sarana Fisik Terhadap Kepuasan Konsumen pada Kafe Doeren Manis Surabaya. (Jurnal Ekonomi, Vol 2, Hal 3, September 2013).

Nur Wulandari Permata. 2013. Analisis Pengaruh Keragaman Produk, Kualitas Pelayanan dan Lokasi Terhadap Kepuasan Konsumen Kopikita Semarang. (Jurnal Bisnis \& Birokrasi, Vol 4, Hal 2, Agustus 2013).

Robbins, Stephen P. dan Coulter Mary. 2012. Manajemen, Edisi Kesepuluh, Jakarta: Erlangga.

Singarimbun, Masri dan Sofyan Effendi. 2000. Metode Penelitian Survey. Jakarta: LP3ES

Stanton, William J, 2013. Alih bahasakan Buchari Alma prinsip-prinsip pemasaran, jilid 1 Edisi ke 3, Alih bahasa oleh Yohanes Lamarto, Jakarta: Erlangga.

Stanton. 2014. Manajemen Pemasaran dan Pemasaran Jasa. Alih Bahasa: Buchari Alma. Bandung: Alfabeta

Sugiyono, 2013. Metode Penelitian Kuantitatif, Kualitatif \& RND. Bandung: Alfabeta. Sugiyono. 2012. Metode Penelitian Kuantitatif Kualitatif dan R\&B. Bandung: Alfabeta.

Sumarni dan Soeprihanto. 2010. Pengantar Bisnis: Dasar-Dasar Ekonomi Perusahaan, Cetakan Keempat, Liberty Yogyakarta.

Widodo, Jasniko. 2013. "Pengaruh Atmosphere Toko dan Variasi Produk terhadap Keputusan Pembelian Konsumen pada Swalayan Citra Bandar Padang". Jurnal Manajemen. Universitas Putra Indonesia "YPTK" Padang. 